\title{
STUDY OF THE END RESULTS AND ASSESSMENT OF AUTONOMIC FUNCTIONAL CHANGES FOLLOWING EARLY MANAGEMENT OF DIAPHYSEAL FRACTURE OF TIBIA BY INTERLOCKING NAILING IN YOUNG ADULTS
}

\author{
Tapan Kumar Das ${ }^{1}$, Anupam Debnath ${ }^{2}$
}

${ }_{1}^{1}$ Associate Professor, Department of Orthopaedics, AGMC, Agartala, Tripura.

${ }^{2}$ Registrar, Department of Orthopaedics, AGMC, Agartala, Tripura.

\begin{abstract}
BACKGROUND
ABSTRACT

Tibia is a large bone of the body and one of the principal load bearing bones in lower extremity. Non-operative treatment of tibial fractures is associated with a high prevalence of malunion, stiffness of the joint \& poor functional outcome. Intramedullary interlocking nailing is a technique which allows stable reduction and early mobilisation. The assessment of autonomic functions is an important part of the evaluation of peripheral and central nervous system.

The Aim of the study was to assess the end results and autonomic functional status in tibial fracture treated by early interlocking intramedullary nailing in young adults.
\end{abstract}

\section{MATERIALS AND METHODS}

56 patients in the age group of 18-40 years who presented with diaphyseal fractures of tibia were studied from November 2013 to October 2015 ( 2 years). Average followup was 7 months. Immediate heart rate response to standing (30:15 R-R ratio) was done to assess the parasympathetic function. Cold Pressor Response (CPR) was done to assess the sympathetic function.

\section{RESULTS}

The average duration of partial weightbearing was 3 weeks. The average duration of full weightbearing was 14 weeks. The average time of healing was 17 weeks. All patients except 2 showed normal parasympathetic function (30:15 R-R ratio). All patients except 2 showed normal sympathetic function (Cold Pressor Test).

\section{CONCLUSION}

Due to lack of information about autonomic functions of the patients before fracture and small sample size, further studies are needed to assess changes in autonomic functions of the patient following this procedure. Because of the high union rate and low infection rate, we consider closed interlocking nailing as the best mode of treatment for diaphyseal tibial fractures.

\section{KEYWORDS}

Tibia, Interlocking, Nailing, Autonomic.

HOW TO CITE THIS ARTICLE: Das TK, Debnath A. Study of the end results and assessment of autonomic functional changes following early management of diaphyseal fracture of tibia by interlocking nailing in young adults. Dent. Sci. 2017;6(90):63536355, DOI: $10.14260 /$ jemds/2017/1382

\section{BACKGROUND}

Tibia is a large bone of the body and one of the principal load bearing bones in lower extremity. Fractures can cause prolonged morbidity, extensive disability unless treatment is appropriate. ${ }^{1}$ The annual incidence of tibial shaft fracture is 26 per 100000 individuals. Males are more commonly affected than females. ${ }^{2}$ Non-operative treatment of tibial fractures is associated with a high prevalence of malunion, stiffness of the joint and poor functional outcome. Plating resulted in higher incidence of non-union, infection and fixation failure. ${ }^{3}$ Advantages of intramedullary nailing 4 are closed reduction and preservation of periosteal blood supply, early mobilisation of knee and ankle joint and early bone union. Locked intramedullary nailing is currently considered

'Financial or Other Competing Interest': None.

Submission 30-08-2017, Peer Review 07-11-2017,

Acceptance 13-11-2017, Published 20-11-2017.

Corresponding Author:

Dr. Anupam Debnath,

Vill- Kashipur, Mission Road,

P. O. Reshambagan, Agartala, Tripura-799008

E-mail: anupamdebnath54@gmail.com

DOI: $10.14260 /$ jemds $/ 2017 / 1382$ the treatment of choice for most tibial shaft fractures. ${ }^{5}$ The assessment of autonomic functions is an important part of the evaluation of peripheral and central nervous system. The autonomic function tests are reliable, reproducible, simple, quick to carry out and all non-invasive. Autonomic function tests are classified as parasympathetic and sympathetic function tests. ${ }^{6}$ The study was done to assess the end results and autonomic functional status in tibial fracture treated by early interlocking nailing, to study the rate and quality of bony union, complications of interlocking nailing in tibia and to determine the autonomic functional improvement after the procedure.

\section{MATERIALS AND METHODS}

The study was done among 56 patients of 18 to 40 years age group, who presented with diaphyseal fractures of tibia, closed fractures, open type-I fractures, segmental fractures, comminuted fractures in Department of Orthopaedics of Agartala Government Medical College and Hospital from November 2013 to October 2015 prospectively. Patients were followed up for a period of 4 months to 2 years (average followup was 7 months). Patients with open fractures type-II and type-III, associated with head injury, pathological 
fractures were excluded from this fstudy. Finally, 56 patients were included in this study as 12 patients were lost to followup. Patients were followed up every 4 weeks, 8 weeks, 12 weeks, 16 weeks, then every 8 weeks. Clinical, Radiological and autonomic functional assessment was done in each followup.

\section{Autonomic Function Tests}

1. To assess the parasympathetic function: Immediate heart rate response to standing (30:15 $\mathrm{R}-\mathrm{R}$ ratio).

2. To assess the sympathetic function: Cold Pressor Response (CPR).

Immediate Heart Rate Response to Standing (30:15 R-R Ratio):

Patient was asked to lie supine quietly on a couch for 15 minutes with Sphygmomanometer \& ECG leads attached. The resting ECG (lead II) was recorded and the baseline heart rate and the resting $\mathrm{BP}$ also measured. Then the subject was asked to stand and remain motionless. A continuous ECG was recorded for 1-3 minutes. The BP was measured at 1 and 3 minutes after standing. HR was noted at the 15th and 30th beat after standing. 30:15 R-R ratio was calculated and compared with the normal value.

\section{Cold Pressor Response}

The patient was asked to sit on a chair and the baseline BP was recorded. The subject was asked to immerse his hand in cold water maintained at 40-60 C; the BP was recorded from the other arm at $30 \mathrm{sec}$. interval for a period of 2 minutes. After 2 minutes the subject was allowed to remove the hand. Maximum increase in systolic and diastolic BP was determined and it was compared with the normal.

The end results were assessed on the basis of $\mathrm{Alho}^{7}$ and Ekeland8 criteria.

\section{This Criteria Considers Six Aspects}

- Tibial mal-alignment and shortening.

- Range of knee motion \& extensor lag.

- Range of ankle motion.

- Foot Motion.

- Pain in limb.

- Swelling.

\section{RESULTS}

We had studied 56 patients until final followup. Majority of the patients $(40 \%)$ were from $36-40$ years age group followed by 31-35 years age group (32\%). Fractures of tibia were found to be more common in males i.e. 44 (78\%) as against females 12 (22\%). Right-sided tibia fracture was seen among 42 patients (75\%). Road traffic accidents were found to amount for most of the injuries $(44,78 \%)$ and fall from height to $22 \%$ cases. Most of the fractures requiring fixation were either in the distal third of the shaft $(28,50 \%)$ or middle third $(20,36 \%)$. The average duration of partial weightbearing was 3 weeks (range 2 to 4 weeks). The average duration of full weightbearing was 14 weeks (range 12-16 weeks). The average time of healing was 17 weeks. 20 $(36 \%)$ fractures healed in 16 weeks, $28(50 \%)$ in 18 weeks, 6 $(17.24 \%)$ in 20 weeks and $2(3.45 \%)$ in $>20$ weeks. Superficial wound infection was encountered in 4 patients. No patient developed deep infection. In 8 cases, there was delayed union so dynamisation was done. Fractures healed satisfactorily. Patients developed anterior knee pain. 82.14\% of patients had excellent results, $14.27 \%$ showed good results. No patient had poor results.

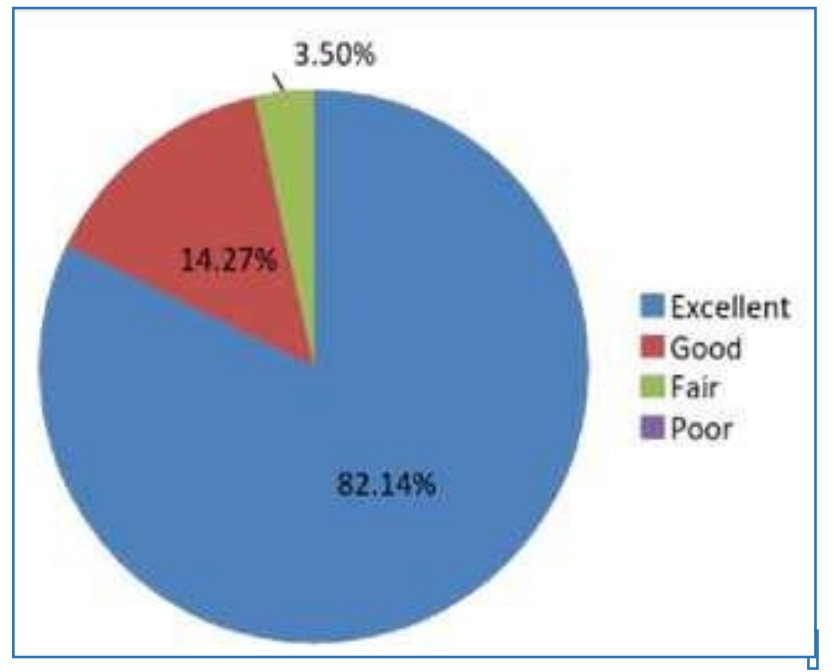

All patients except 2 patients showed normal parasympathetic function (30:15 R-R ratio).

All patients except 2 patients showed normal sympathetic function (Cold Pressor Test).

\section{DISCUSSION}

Majority of the patients in this study were in the age group of 35-40 years. Ekeland et $\mathrm{al}^{8}$ (1988), in their study series of 45 patients noted the mean age of patients to be 35 years. Hooper et $\mathrm{al}^{9}$ (1991) showed that the incidence of fracture had male preponderance (82\%). In our study, incidence in male was $78.5 \%$. In our study, 44 patients $(78.5 \%)$ of the tibial diaphyseal fractures occurred due to road traffic accidents. Majority of cases were the motorists. Lawrence B Bone et $\mathrm{al}^{10}$ (1986) reported a $90 \%$ incidence of road traffic accidents in tibial shaft fractures. In our series, the anatomical location of the fracture was in the distal-third of the shaft of tibia in $28(50 \%)$ patients, followed by the mid third in $20(36 \%)$.

Court Brown et al ${ }^{11}$ (1995) showed $44 \%$ were middle third fractures. The shaft of the tibia is the narrowest at the junction of its middle and inferior thirds, which is the most frequent site of fracture. Larsen et al studied 45 patients with reamed interlock nail in whom average time to fracture healing was 16.7 weeks and had two malunions while in our study healing time was 17 weeks with no malunion. In our series, majority of fractures united within 20 weeks (48 patients). Anglen J0 et al ${ }^{12}$ (1995) showed average union time of 22.5 weeks, Lawrence B Bone et al $^{10}$ reported average time of union 19 weeks. In our series, 4 patients (7\%) had superficial wound infection of the proximal incision site. This responded to the oral antibiotics and dressings. We had no case of broken or bent nail. No case of bent or broken screw reported. We had no compartment syndrome, lateral popliteal nerve palsy or fat embolism. Few patients experienced anterior knee pain, pain at fracture site and locking bolt in treatment phase, most of them recovered after sound union, physiotherapy and analgesics.

The assessment of autonomic function is an important part of the evaluation of the peripheral and central nervous 
system. Abnormalities of autonomic function lead to different clinical entities like orthostatic hypotension, sexual dysfunction, diarrhoea, incontinence, dryness of mouth and so on. Autonomic function tests are performed to confirm the clinical diagnosis of autonomic neuropathies and to assess the intactness of the sympathetic and parasympathetic pathways.

We examined both sympathetic (Cold pressor test) and parasympathetic (30:15 R-R ratio) system. Only 2 patients (3.6\%) showed abnormal sympathetic and parasympathetic function. Those patients were known diabetics. Before injury no data about autonomic system was available, so those patients might have had poor autonomic function before fracture. Ghai C L stated that in some normal persons there might be no significant rise in BP after cold pressor test. Mourot et al ${ }^{13}$ said that further studies are needed to explain why healthy subjects react differently to the CPT and if this has potential clinical implications.

\section{CONCLUSION}

The incidence of tibial diaphyseal fractures in young adults has increased significantly during recent decades and this tendency will probably continue in the near future due to high energy trauma. The goal of the treatment of these fractures is stable fixation, which allows early mobilisation of the patient so that complications of prolonged immobilisation can be avoided and early return to function can be done. Due to lack of information about autonomic functions of the patients before fracture and small sample size, further studies are needed to assess changes in autonomic functions of the patient following this procedure. Because of the high union rate and low infection rate, we consider closed interlocking nailing as one of the best mode of treatment for diaphyseal tibial fractures.

\section{REFERENCES}

[1] Wilson JN. Watson-Jones fracture and joint injuries. Chapter 32, 7th edn. Elsevier, 2009:pp 949.

[2] Bucholz RW, Heckman JD, Brown CC. Rockwood and greens fractures in adults. Chapter 52. $6^{\text {th }}$ edn. Lippincott Williams and Wilkins, 2006:pp 20.
[3] Tornetta P, Bergman M, Watnik N, et al. Treatment of grade-IIIb open tibial fractures. A prospective randomized comparison of external fixation and nonreamed locked nailing. J Bone Joint Surg $\mathrm{Br}$ 1994;76(1):13-9.

[4] Ellis $H$. The speed of healing after fracture of the tibial shaft. J Bone J Surg (Br) 1958;40B(1):42-6.

[5] Canale ST, Daugherty K, Jones L. Campbell operative orthopaedics. 12th edn. Vol 3. Philadelphia: Mosby, 2013:pp 2644.

[6] Jain AK. Manual of practical physiology. $3^{\text {rd }}$ edn. Unit III, Chapter 25. Delhi, Arya Publications, 2010:279-84.

[7] Alho A, Benterud JG, Hogevold HE, et al. Comparison of functional bracing and locked intramedullary nailing in the treatment of displaced tibial shaft fractures. Clin Orthop Relat Res 1992;(277):243-50.

[8] Alho A, Ekeland A, Strømsøe K, et al. Locked intramedullary nailing for displaced tibial shaft fractures. J Bone Joint Surg Br 1990;72(5):805-9.

[9] Hooper GJ, Keddell RG, Penny ID. Conservative management of closed nailing for tibial shaft fracture. A randomized prospective trial. J Bone Joint Surg $\mathrm{Br}$ 1991;73(1):83-5.

[10] Bone LB, Johnson KD. Treatment of tibial fractures by reaming and intramedullary nailing. J Bone Joint Surg Am 1986;68(6):877-87.

[11] Court-Brown CM, Christie J, McQueen MM. Closed intramedullary tibial nailing. Its use in closed and type I open fractures. J Bone Joint Surg Br 1990;72(4):60511.

[12] Anglen JO, Blue JM. A comparison of reamed and undreamed nailing of the tibia. J Trauma 1995;39(2):351-5.

[13] Mourot L, Bouhaddi M, Regnard J. Effects of the cold pressor test on cardiac autonomic control in normal subjects. Physiol Res 2009;58(1):83-91. 